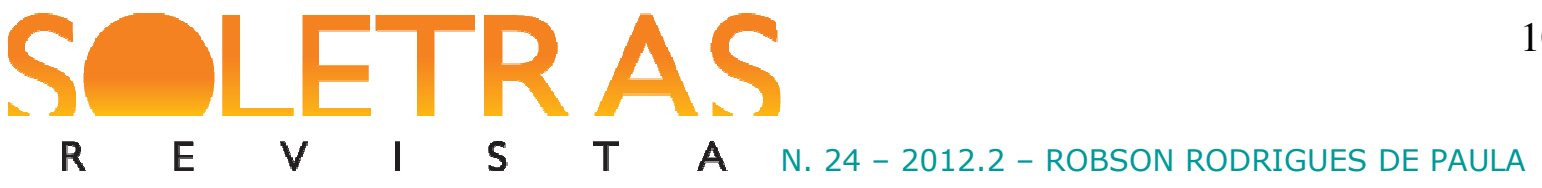

\title{
Diálogos intersemióticos: interacionismo e pintura impressionista em cena ${ }^{1}$
}

\author{
Robson Rodrigues de Paula ${ }^{2}$
}

Resumo: A formação de os grandes centros urbanos no Ocidente a partir do século XIX fomentou significativas mudanças nas relações sociais e no modo de apreensão do espaço público pelos sujeitos. No presente ensaio, de forma introdutória, analiso a forma com que o interacionismo, escola importante da sociologia, e a pintura impressionista compreenderam ou expressaram, por meio de seus referenciais teóricos ou estéticos, os encontros e desencontros de indivíduos e de segmentos sociais em Chicago, lócus de estudo dos sociólogos interacionistas, e Paris, cidade protagonista do impressionismo na pintura. Defendo, ao longo do artigo, a existência de alguns pontos de contato entre ambas as expressões humanas, principalmente a respeito de seus procedimentos e técnicas, usados no ato de criação.

Palavras-chave: Interacionismo. Pintura Impressionista. Sociologia da Arte. História cultural.

\begin{abstract}
Os cidadãos urbanos usurparam o direito de dissolver os laços da dominação senhorial - e esta foi a grande inovação, de fato, a inovação revolucionária das cidades medievais do Ocidente em face de todas as outras- a quebra do direito senhorial. Nas cidades centro e norte europeias originou-se o conhecido dito: "o ar da cidade liberta".
\end{abstract}

Max Weber

\section{Introdução}

Em “As grandes cidades e a vida do espírito”, publicado em 1903, primorosamente, George Simmel reflete sobre as condições de existência dos indivíduos no espaço urbano. De forma ensaística e assumindo uma perspectiva teórica centrada nas interações individuais, um dos teóricos mais importantes da sociologia analisa as estratégias de defesa adotadas pelos atores sociais em resposta aos inúmeros estímulos nervosos presentes nas grandes cidades. De acordo com a análise de Simmel, em um cenário de conglomeradas edificações e caracterizado pela circulação ampliada de bens, produtos e pessoas, para garantirem a sua

\footnotetext{
1 Agradeço ao Programa de Bolsas de Pesquisa (Proape) do Centro Universitário UNIABEU pela bolsa concedida. Sem ela, não seria possível desenvolver este escrito.

${ }^{2}$ Robson de Paula é mestre e doutor em Ciências Sociais pela Universidade Estadual do Rio de Janeiro (UERJ). Publicou artigos em revistas acadêmicas de grande expressão nacional, como Religião e Sociedade e apresentou comunicações em vários congressos internacionais. Atualmente, além de lecionar nos cursos de graduação de pós-graduação UNISUAM, é professor e pesquisador do Centro Universitário UNIABEU, onde coordena pesquisas que abordam as interfaces existentes entre religião, música e indústria cultural. É membro do Grupo de Pesquisa CNPq, "Poéticas do Contemporâneo". E-mail: rrdepaula@ hotmail.com.
} 


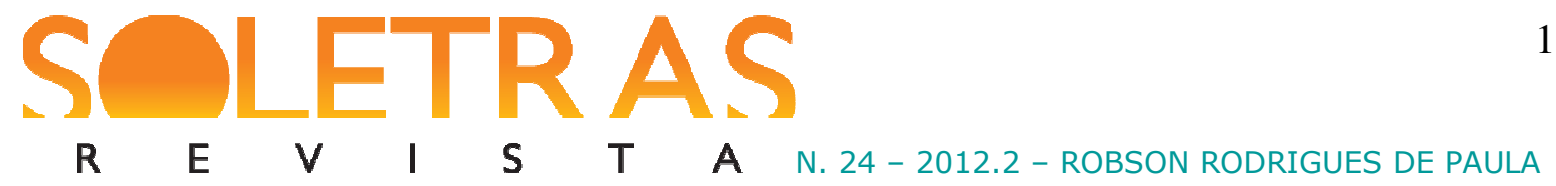

estabilidade psíquica, os indivíduos adotariam uma série de comportamentos, como contatos superficiais, a intelectualização do self e, em várias situações, uma atitude blasé.

Na contemporaneidade, 110 anos após a sua publicação, tal escrito continua sendo uma referência importante para os que se aventuram pelos meandros da antropologia e da sociologia urbanas, por ter privilegiado pioneiramente uma dimensão do problema que até então não tinha sido analisada: os transtornos psicológicos resultantes da vida nos grandes centros.

Simmel não foi o único intelectual no início do século XX a se preocupar com questões relacionado mundo urbano. De modo geral, profissionais de diferentes vertentes do conhecimento abordaram a migração em massa de indivíduos do meio rural para as capitais europeias, principalmente ocorrida a partir do século XIX; refletiram acerca das reformas urbanísticas realizadas em algumas cidades europeias ainda neste período; avaliaram as consequências sociais e habitacionais decorrentes da formação das metrópoles dos EUA e da Europa, no início dos anos 1900; e, por fim, contemplaram também o cotidiano, as relações sociais e a movimentação dos transeuntes no espaço urbano. Inúmeras foram as ênfases, as questões e as abordagens realizadas, demonstrando que a cidade e os seus moradores são bons materiais de estudo ou ótimos objetos para serem representados artisticamente.

No presente ensaio, de forma introdutória, analiso a forma com que o interacionismo, escola importante da sociologia, e a pintura impressionista refletiram sobre o urbano, principalmente a respeito da interação social nos grandes centros. Em outras palavras, investigarei o modo como esses profissionais compreenderam ou expressaram, por meio de seus referenciais teóricos ou estéticos, os encontros e desencontros de atores e grupos sociais nas grandes cidades, principalmente em Chicago, lócus de estudo dos sociólogos interacionistas, e em Paris, cidade protagonista do impressionismo na pintura.

Ao propor esta reflexão comparativa, inspiro-me em Robert Nisbet (2000), o qual atesta uma interligação necessária entre o que chamamos no ocidente de arte e as ciências - em especial a sociologia. De acordo com Nisbet, a ideia de que estes campos são ontologicamente distintos e excludentes entre si é falaciosa, uma vez que, decorreria, por um lado, da crença difundida largamente pelos artistas românticos do século XIX, de que o ato de criação artístico é resultante de uma suposta genialidade e não de o trabalho técnico e experimental; por outro, da defesa irrestrita do método científico, realizada pelos cientistas também daquele período, a qual serviu como base para profissionalização da ciência. Portanto, tal distinção de 
$\begin{array}{lllllllll}\mathbf{R} & \mathbf{E} & \mathbf{V} & \mathbf{I} & \mathbf{S} & \mathbf{T} & \mathbf{A} & \text { N. } 24-2012.2-\text { ROBSON RODRIGUES DE PAULA }\end{array}$

fronteiras é uma produção histórica do século XIX. Vale salientar que, ao defender esta tese, o pensador estadunidense não está desconsiderando as especificidades existentes entre estas produções humanas e, tampouco, está propondo uma fusão entre elas. Nisbet quer dar relevo a intercambialidade observadas entre os referidos campos profissionais, sobretudo pelo fato de igualmente buscarem a compreensão da "realidade", além de desenvolverem também relações significativas. Em suas próprias palavras,

O interesse do artista na forma é o interesse do cientista na estrutura. Em cada um, o desejo de visão e entendimento é dominante. Cada um trabalha empiricamente; luta para comunicar sua descoberta através de uma produção, ou uma estrutura formal que requer técnica para ser dominado. Vale a pena notar que a palavra "teoria" origina-se da mesma raiz grega da palavra "teatro". Ela significa, basicamente, olhando fixamente para, contemplação. Está ligada à palavra imaginação - ou seja, literalmente, internalizar o mundo externo em uma imagem que a mente retém com tenacidade. Em suma, arte e ciência dependem, ambas, da capacidade de se distanciar e da habilidade de abster-se de compromissos (NISBET, 2000, p. 117-118).

Seguindo os passos de Nisbet, apresentarei, na próxima seção, os contextos histórico e acadêmico nos quais a sociologia interacionista surgiu, para, em seguida, indicar como que os expoentes desta matriz de conhecimento perceberam as interações no espaço público de Chicago. Em seguida, discorrerei sobre a maneira como os pintores impressionistas representaram as interações desenvolvidas pelos diversos atores sociais em Paris, num período caracterizado por grandes transformações urbanísticas, culturais, econômicas e políticas. Ao longo do ensaio, salvaguardando as devidas diferenciações, indicarei algumas semelhanças existentes entre estas expressões humanas, principalmente acerca de seus modos e procedimentos de criação.

\section{A Escola de Chicago e o paradigma interacionista}

Em 1895, após a doação significativa do milionário John Davison Rockefeller, foi criado o Departamento de Sociologia da Universidade de Chicago. Inicialmente sob a coordenação do sociólogo Albion Small, o grupo de pesquisa em questão contava com poucos professores. À ocasião, como bem colocou Becker (1996), a proposta principal do núcleo era formar novos doutores a partir do modelo alemão - principalmente o instituído por Simmel, presente no artigo mencionado na introdução - e, como efeito, propagar a nova ciência em 


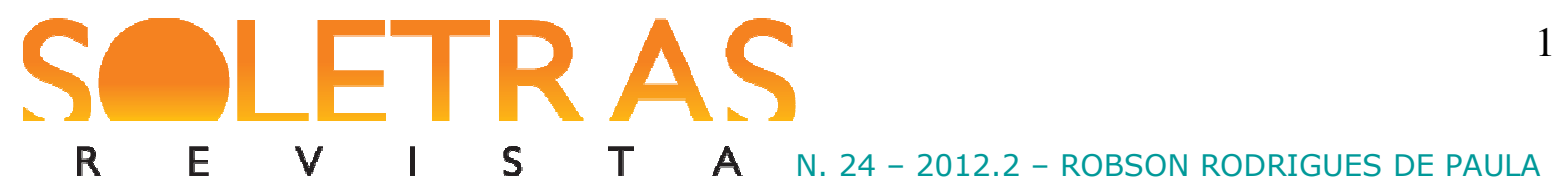

todo território norte americano. Seguindo essa perspectiva de institucionalização e estruturação do campo da sociologia nos EUA, além dos cursos ministrados, foi criada a primeira revista de sociologia americana, a American Journal of Sociology, considerada uma das principais publicações científicas da área até os dias atuais.

Ainda na tentativa de organizar e legitimar o departamento como um lócus de produção de conhecimento científico sobre a sociedade, buscou-se o estudo dos principais problemas sociais que afligiam os cidadãos americanos naquela época, sobretudo os moradores da cidade de Chicago. Individualmente ou com grupos de alunos, os professores do departamento em questão pesquisaram, com afinco, questões e dinâmicas sociais relacionadas à pobreza, à migração, à segregação étnica e, de modo mais amplo, aos conflitos existentes na região metropolitana daquela cidade. Ainda segundo Becker (1996), subjacente a esses trabalhos, que em sua grande maioria adotava uma perspectiva menos teórica e mais empírica, repousava um ideal político de reforma social. Seguindo, então, essas orientações temáticas e metodológicas, a Escola de Chicago, como passou a ser conhecida, instituiu uma das principais vertentes analíticas da sociologia: o interacionismo.

Em linhas gerais, em suas observações, os interacionistas priorizam o estudo das relações sociais, desenvolvidas pelos atores em um espaço circunscrito, que pode ser uma instituição total, uma organização empresarial, pequenas unidades territoriais - determinadas áreas urbanas, distritos, bairros etc. - ou até mesmo uma unidade de análise mais ampla e complexa, como uma cidade. Não faz parte, portanto, do horizonte metodológico destes pesquisadores uma investigação de ordem mais macroestrutural, nem uma análise mais diacrônica, fato que suscitou várias críticas de pensadores, engajados em promover contextualizações, generalizações ou inferir recorrências históricas entre os fenômenos observados. Segundo Benenice Fisher e Anseln Strauss (1980), existem pelo menos duas tradições interacionistas, formadas em momentos históricos distintos, por duas gerações de pesquisadores que se sucederam. A primeira teria sido instituída logo após a criação do departamento, nos anos 20, por George Mead (1863-1931), concebido como o formulador desta perspectiva analítica, Robert E. Park (1864-1944) e William I. Thomas (1863-1947), entre outros. Grosso modo, as relações interraciais, a delinquência juvenil e os "elementos desviantes" se destacaram no repertório temático analisado por eles.

Posteriormente, os seus alunos, orientandos e assistentes de pesquisa não somente assumiram as coordenações de pesquisa, dando continuidade ao empreendimento intelectual iniciado, como também formaram novos núcleos de investigação sociológica em outras 
$\begin{array}{lllllllll}\mathbf{R} & \mathbf{E} & \mathbf{V} & \mathbf{I} & \mathbf{S} & \mathbf{T} & \mathbf{A} & \text { N. } 24-2012.2-\text { ROBSON RODRIGUES DE PAULA }\end{array}$

universidades estadunidenses. Dentre eles, destacaram-se Erving Goffman (1922-1982); Everett Hughes (1897- 1983); e Howard Becker (1982-). De acordo com Fisher e Strauss (1980), tais pensadores constituíram a segunda geração da tradição interacionista e contribuíram, cada um a seu modo, para o fortalecimento e visibilidade do departamento de sociologia no cenário mundial, por continuarem tomando como unidade de análise segmentos de Chicago e por usarem, quase sempre, a abordagem qualitativa em seus estudos.

\section{Park e o desenvolvimento de um programa de estudo da cidade}

No texto "A cidade: sugestões para a investigação do comportamento humano no meio urbano", publicado originalmente no American Journal of Sociology, em 1916, Park elaborou um programa de questões que deveria ser estudado sobre o espaço urbano. Inspirado na abordagem antropológica de sua época, principalmente as adotadas por Frans Boas (18581942), Park sugeriu que os objetos da sociologia urbana deveriam ser os costumes, os hábitos e as práticas sociais dos habitantes citadinos. Em outros termos, na perspectiva deste estudioso, a cidade deveria ser compreendida, não a partir de suas formas física e funcional, mas como um espaço "vivo", dotado de um "espírito" próprio, como observa-se na citação a diante:

[...] A cidade é algo mais do que um amontoado de homens individuais e de conveniências sociais, ruas edifícios, luz elétrica, linhas de bonde, telefones etc.; algo mais também do que uma mera constelação de instituições e dispositivos administrativos civis de vários tipos. Antes, a cidade é um estado de espírito, um corpo de costumes e tradições e dos sentimentos e atitudes organizados, inerentes a esses costumes e transmitidos por essa tradição. Em outras palavras, a cidade não é meramente um mecanismo físico e uma construção artificial. Está envolvida nos processos vitais das pessoas que a compõem; é um produto da natureza, e particularmente da natureza humana (PARK, 1973, p. 26).

Adotando essa concepção mais ampla e dinâmica acerca da configuração do urbano, em suas incursões empíricas, Park constatou uma tendência geral de desagregação das relações familiares e de vizinhança e, em contrapartida, um aumento significativo de vínculos sociais transitórios e efêmeros em Chicago. A consolidação do modelo econômico industrial capitalista - associado à emergência da cultura do consumo - e a grande circulação de pessoas seriam, na interpretação deste sociólogo, os principais fenômenos relacionados à difusão 


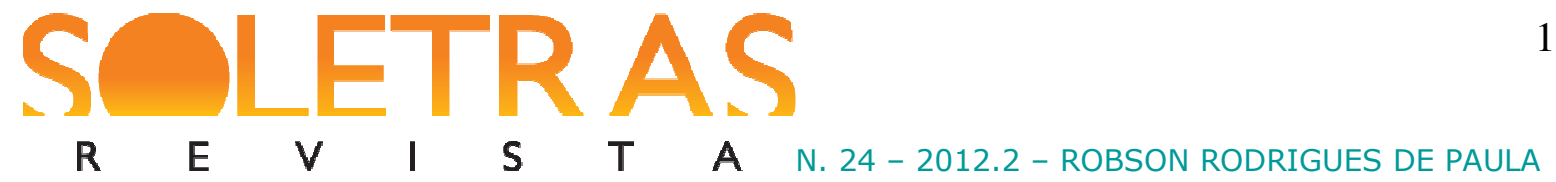

ampliada de relações secundárias, em detrimento das fundamentadas nos laços de parentesco e na afetividade, conforme ainda nos relata a seguir:

\begin{abstract}
Numa cidade grande, onde a população é instável, onde pais e filhos estão empregados fora de casa e muitas vezes em partes da cidade distantes, onde milhares de pessoas vivem lado a lado durante anos sem nem ao menos um conhecimento de cumprimentar, essas relações íntimas do grupo primário se enfraquecem, e a ordem moral que sobre elas repousava dissolve-se gradativamente (PARK, 1973, p. 47).
\end{abstract}

Além de produzirem um impacto negativo nas famílias e, com efeito, terem contribuído para o enfraquecimento da ordem moral, as novas configurações econômicas, observadas naquela metrópole estadunidense no início do século $\mathrm{XX}$, causaram o aumento da criminalidade e do consumo das drogas ilícitas, principalmente entre os jovens (PARK, 1973). Contudo, torna-se necessário fazer uma ressalva a respeito desta observação. Em algumas áreas específicas da cidade, Park identificou um movimento inverso. Nos bairros estigmatizados - comunidade que concentravam a população negra - e nas colônias de imigrantes, as relações de vizinhanças permaneceram fortalecidas, independentemente da tendência mais ampla de dissolução da ordem moral. Por serem discriminados pela sociedade abrangente, os segmentos minoritários em questão mantiveram coesos os seus vínculos sociais, num movimento estratégico de sobrevivência e autopreservação.

O fortalecimento interno dessas comunidades, bem como seu afastamento dos demais segmentos sociais, contribuíam para formação de diferentes "regiões morais" na cidade de Chicago (PARK, 1973). Apesar de o espaço urbano ter se transformado em um verdadeiro "mosaico" de diferentes mundos fragmentados - e assumindo assim um caráter mais "superficial" e "adventício" -, entre esses grupos, o compartilhamento de valores, costumes e crenças não teria desaparecido.

Igualmente a Park e à Escola de Chicago, de modo geral, os pintores impressionistas também se sensibilizaram a respeito da forma com que os indivíduos passaram a se relacionar entre si e com a cidade, em um contexto também marcado por grandes transformações urbanísticas. Embora exista uma descontinuidade temporal - o auge do impressionismo ocorreu no final do século XIX, portanto, duas décadas anteriores à produção sociológica de Park - e um afastamento geográfico - o impressionismo foi um movimento artístico europeu, fundamentalmente francês, e não estadunidense -, pode-se estabelecer uma aproximação entre eles, uma vez que contemplaram igualmente as novas modalidades de interações sociais na 


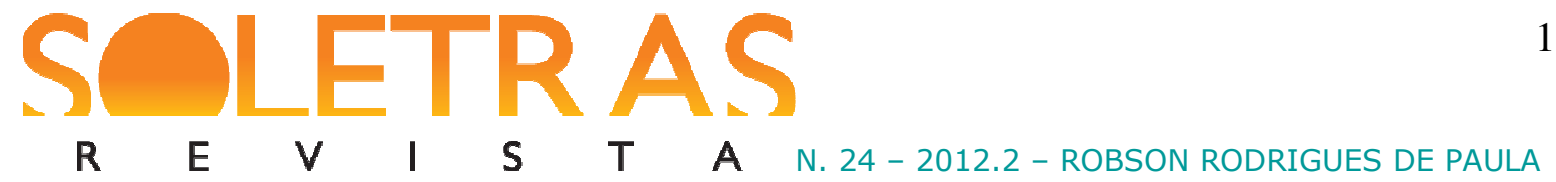

paisagem das cidades emergentes, além desenvolverem um procedimento de criação bastante semelhante, salvaguardando, é claro, as devidas proporções. Antes de desenvolver este ponto, torna-se necessário apresentar as características temáticas e estéticas da pintura impressionista.

\section{A modernização de Paris e a pintura impressionista}

O Salão Oficial era o local mais concorrido pelos pintores franceses, que almejavam expor as suas produções, em Paris, no século XIX. A aceitação da obra por parte dos críticos desta galeria de artes influenciava significativamente a recepção do grande público e determinava, com efeito, o reconhecimento do artista. As produções que não estivessem em conformidade com os padrões da arte vigente, os quais eram utilizados para definir um "bom quadro", eram sumariamente descartadas pelos profissionais deste núcleo de arte e pela crítica em geral. Cansados de terem suas obras recorrentemente rejeitadas pelo Salão Oficial, por destoarem esteticamente do paradigma artístico instituído naquele período, um grupo de jovens pintores decidiu montar uma mostra de arte alternativa, em Paris, em 1874, a qual foi denominada por eles próprios como a exposição da Sociedade Anônima de Artistas, Pintores, Escultores, Gravadores etc. Contudo, após ter avaliado um dos quadros expostos, a Impression, Soleil Levant (Impressão, Nascer do Sol), de Claude Monet (1840-1926), o dramaturgo e crítico de artes Louis Leroy chamou este encontro de Exposição dos Impressionistas, uma categorização que flagrantemente expressava uma atitude negativa deste profissional não somente acerca da obra avaliada como também de todos os outros quadros expostos (REYNOLD, 1990; HARRISON, 2001; SCHAPIRO, 2002). Posteriormente, esta denominação foi ressignificada e passou a ser utilizada positivamente para fazer referência a um dos primeiros movimentos modernistas, concebido com um marco importante na história da pintura mundial.

Entre os estudiosos das artes, há um consenso de que o impressionismo instituiu uma verdadeira ruptura na história da pintura, não somente por indicar novos temas e técnicas pictóricas, como também por sugerir uma postura mais ativa do pintor com relação aos objetos e pessoas em seu entorno, no momento de criação artística. Embora tenham retratado as paisagens urbanas e suburbanas como os realistas faziam até então, os impressionistas inovaram na maneira com que as capturaram e as representaram. Inspirados na fonografia, 


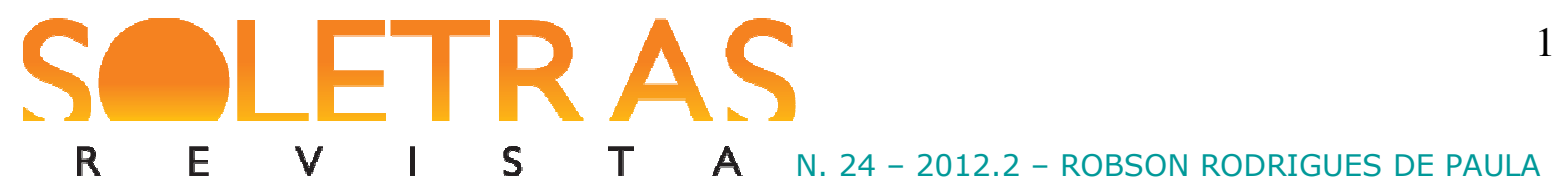

delicadamente, procuraram capturar o instante fugaz, o tempo real, a luz e os jogos de sombras sobre os objetos, edificações e pessoas, conforme o fragmento a seguir:

No plano técnico, os artistas impressionistas vão deixar de representar as formas e as cores tais como pensam que elas são para as mostrarem tal como as vêem sob a ação deformadora da luz. Renunciam assim a alguns princípios tradicionais da arte pictórica. O desenho dos contornos, definindo a forma e sugerindo o volume é banido e substituído por pinceladas fragmentadas, divididas e justapostas (SÉ-RULLAZ, apud CASTRO, 2008, p. 397).

O quadro Impression, Soleil Levant, mencionado anteriormente, é exemplar por indicar perfeitamente tais inovações estéticas adotadas pelos impressionistas. Nele, com pinceladas finas e largas de cores vibrantes e sobrepostas, Monet expôs a maneira como percebeu o nascer do sol, entre névoas, no porto de Havre, focalizando um barco e um estaleiro no centro da tela:

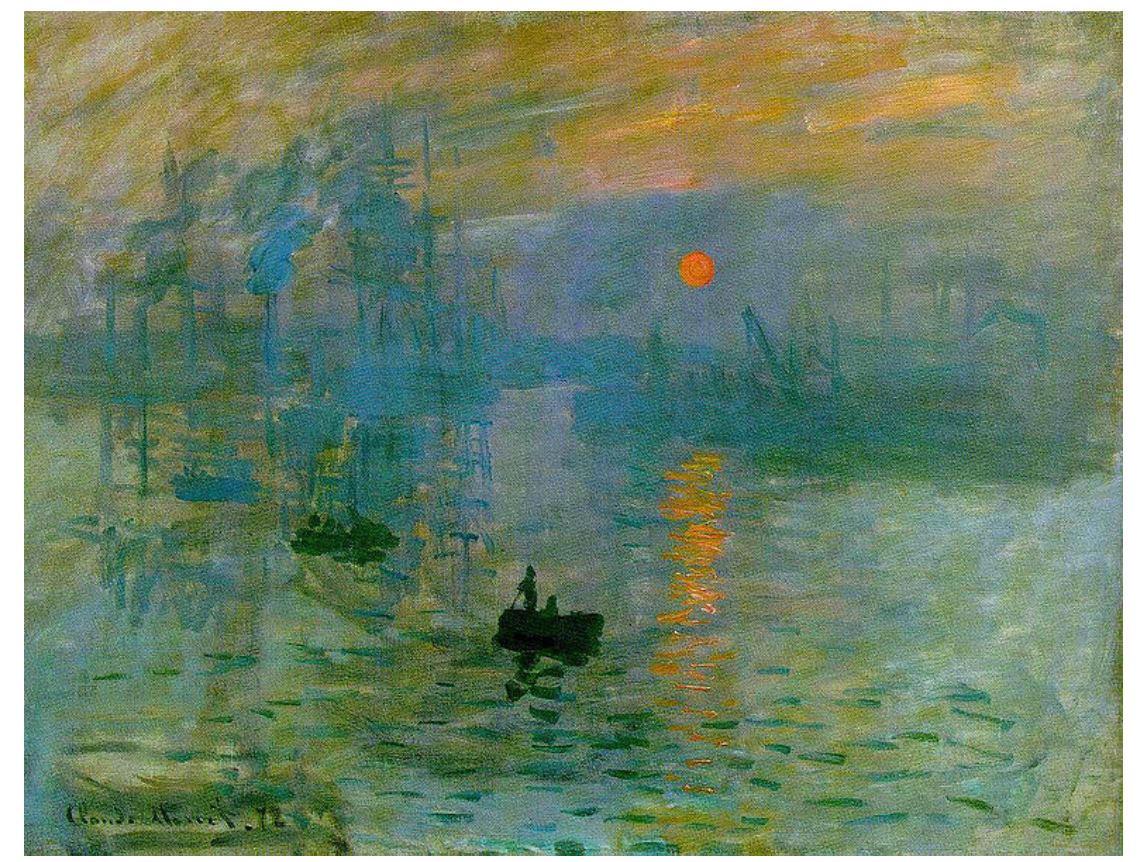

Claude Monet, Impression, Soleil levant., 1872

Camile Pissaro (1830-1903), Édouard Manet (1832-1883), Alfred Sisley (1839-1899), Paul Cézanne (1839-1906), Auguste Renoir (1841-1919) e Edgar Degas (1843-1917), entre outros, também, ao retratarem o Rio Sena, os cafés, os parques, os tipos urbanos e a paisagem da cidade, como um todo, tinham como foco tais orientações técnicas e estéticas. 


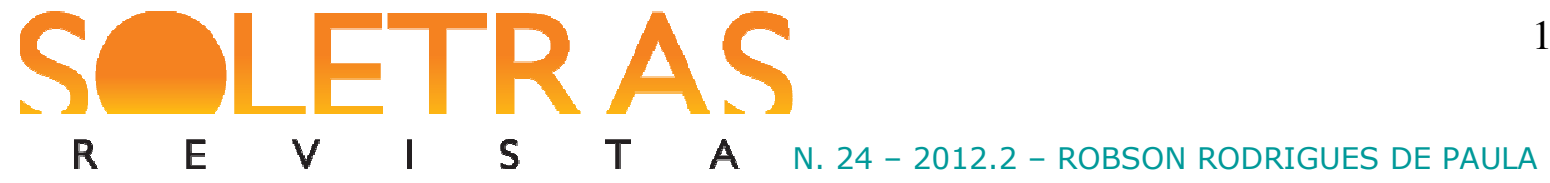

Da mesma maneira que a formulação da abordagem sociológica interacionista está associada às transformações urbanísticas ocorridas em Chicago, observa-se que o impressionismo surgiu e se desenvolveu de forma articulada às profundas mudanças verificadas no espaço urbano de Paris, no século XIX. Nesta perspectiva de análise, com muita propriedade e sofisticação, Clark (1984) estabelece uma relação entre a reforma urbanística parisiense, promovida pelo prefeito do Sena, Georges-Eugène Haussmann (18091891), e a formação do movimento impressionista.

Entre os anos 1853 e 1870, a capital francesa passou por um grande, complexo e custoso processo de reestruturação urbanístico, sem precedentes na história daquele país e que, por essa razão, fomentou controversas, polêmicas e incertezas.

O alargamento das ruas e vielas; a construção de novos espaços de circulação e de entretenimento (praças e bulevares); a criação de novas construções em substituição aos casarões centenários; a instalação de aquedutos mais modernos; e a colocação de lâmpadas de gás possantes foram algumas das várias intervenções arquitetônicas promovidas pelo barão Haussmann, no afã de adequar Paris aos interesses econômicos e culturas da emergente camada dominante. Em outras palavras, a capital francesa, gradativamente, tornou-se a imagem e a semelhança dos burgueses.

Ainda de acordo com Clark (1984), todas essas transformações urbanísticas afetaram a sensibilidade dos atores sociais, instaurando um sentimento de incerteza, insegurança e desconforto. Em um período relativamente curto, os parisienses viram uma nova Paris surgir em meio aos escombros da cidade que estavam acostumados a viver, e que comportava as relações de vizinhança, cujas construções se destacavam pelas formas singulares e pitorescas. Tal modernização pôde ser observada também nas representações pictóricas dos impressionistas.

Por exemplo, ao retratarem o crescimento das fábricas nas regiões limítrofes daquela cidade, procuram indicar o impacto da modernidade no cotidiano e nas antigas relações sociais no campo. No quadro, apresentado a seguir, Pissaro retratou uma típica fábrica francesa do final do século XIX. Em especial, com tons variados de cinza, verde e marrom, Usine à Saint-Quen-L'Aumône indica as novas unidades produtivas, as quais passaram a compor a paisagem dos arredores da capital da França: 
$\begin{array}{llllllll}\mathbf{R} & \mathbf{E} & \boldsymbol{V} & \mathbf{I} & \mathbf{S} & \mathbf{T} & \mathbf{A} & \text { N. } 24-2012.2-\text { ROBSON RODRIGUES DE PAULA }\end{array}$

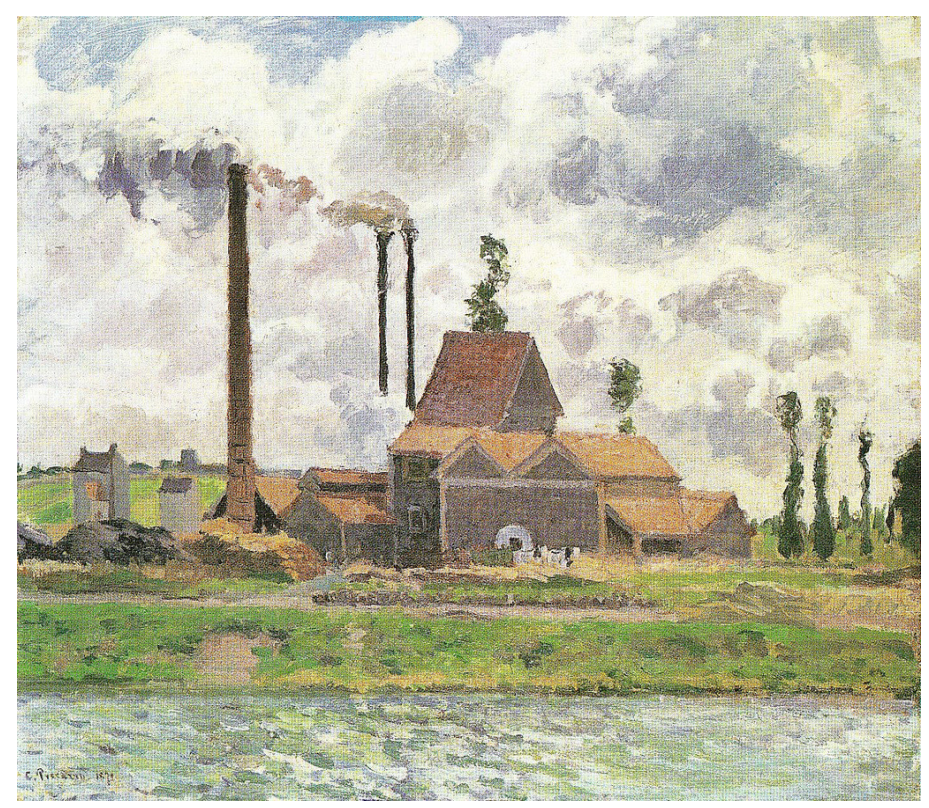

Camile Pissaro, Usine à Saint-Quen-L'Aumône, 1973

Além de retratarem as transformações ocorridas nos territórios entre a cidade e o campo - a banlieue -, os impressionistas representaram pictoricamente a maneira com que os parisienses, principalmente os pertencentes às camadas mais abastadas, se apropriaram do espaço público e dos locais voltados para o entretenimento, criados à ocasião. Conforme já mencionei, a movimentação dos transeuntes elegantes nas largas avenidas da cidade, os passeios de homens e mulheres burgueses nos parques fundados por Haussmann, bem como os encontros e comemorações nos cafés foram demasiadamente focados por essa vertente artística. Produzido por Renoir em 1875, Les Grands Boulevard é uma pintura que expressa, claramente, essa proposta temática impressionista:

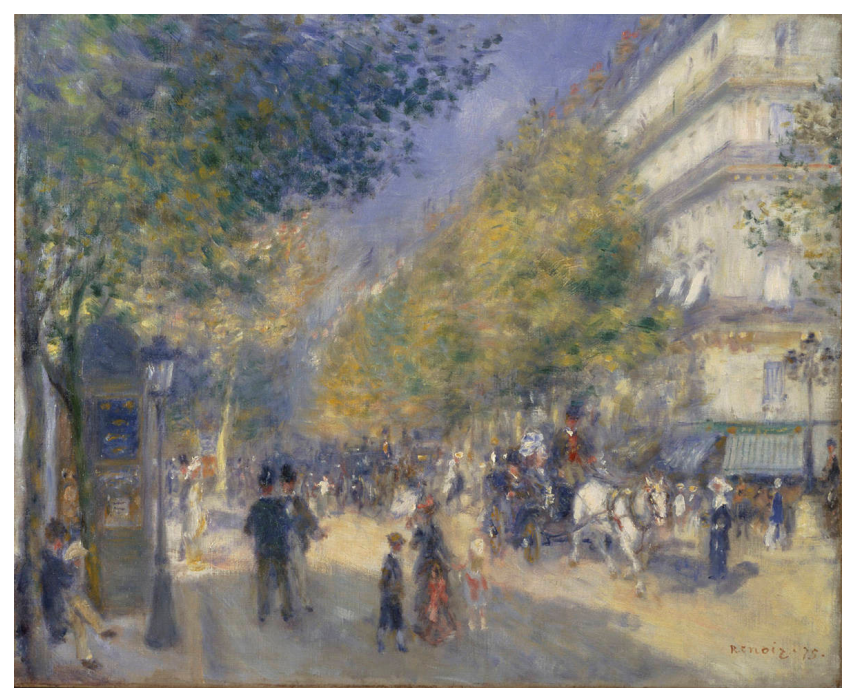

Auguste Renoir, Les Grands Boulevards, 1875 


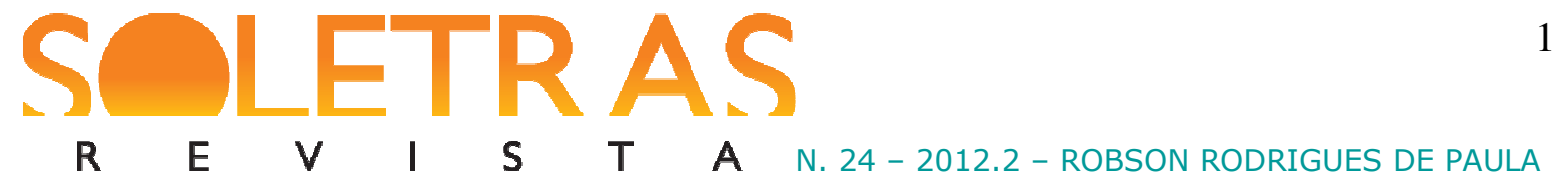

Não somente nesta obra como também em outras produções da pintura impressionista, evidencia-se a proposta de retratar a cidade como um espetáculo, uma imagem a ser consumida, em conformidade com a lógica econômica capitalista, a qual motivou a transformação urbanística e arquitetônica dirigida pelo barão Haussmann:

\begin{abstract}
Ao que tudo indica, a nova imagem não parecia inteiramente diferente das antigas. Ela ainda parecia sugerir que a cidade era um lugar que num certo sentido pertencia àqueles que nela viviam. Mas agora ela lhes pertencia apenas como uma imagem, como algo ocasional e causalmente consumido em espaços concebidos para esse único propósito - passeios, panoramas, programas de domingo, grandes exposições, desfiles oficiais. Ela não podia ser apreendida fora disso; não fazia mais parte daqueles padrões de ação e apropriação que constituíam a vida cotidiana dos espetáculos (CLARK, 1984, p. 76).
\end{abstract}

Decorre daí uma questão: em que medida essa nova concepção da capital francesa, presente nas pinturas impressionistas, está em conformidade cotidiano parisiense?

De acordo com Clark (1984), esse ideário de cidade espetáculo, o qual se constituiu associado ao mito da modernidade, onde todos estariam livres das velhas delimitações sociais tradicionais, deve ser problematizado. Além de ter produzido uma sensação de incerteza e insegurança, como já foi sinalizado, a reforma de Haussmann não fomentou uma maior liberdade dos indivíduos no espaço público. Pelo contrário, acentuou a segregação social, uma vez que os locais da cidade foram divididos em "distritos residenciais" ou "subúrbio industrial" e a população mais pobre foi obrigada a se deslocar para regiões distantes do centro parisiense.

Portanto, mesmo tendo atentado para a grande transformação urbanística ocorrida em Paris e para a maneira com que o espaço público passou a ser apreendido e utilizado pelos moradores da "cidade luz", os pintores não deram relevo, em seus quadros, às contradições sociais que surgiram em meios a essas mudanças. No conjunto das obras impressionistas, observa-se um inexpressivo acervo de pinturas nas quais se faz uma alusão à desigualdade social. Observe-se o quadro a seguir: 
$\begin{array}{lllllllll}\mathbf{R} & \mathbf{E} & \boldsymbol{V} & \mathbf{I} & \mathbf{S} & \mathbf{T} & \mathbf{A} & \text { N. } 24-2012.2-\text { ROBSON RODRIGUES DE PAULA }\end{array}$

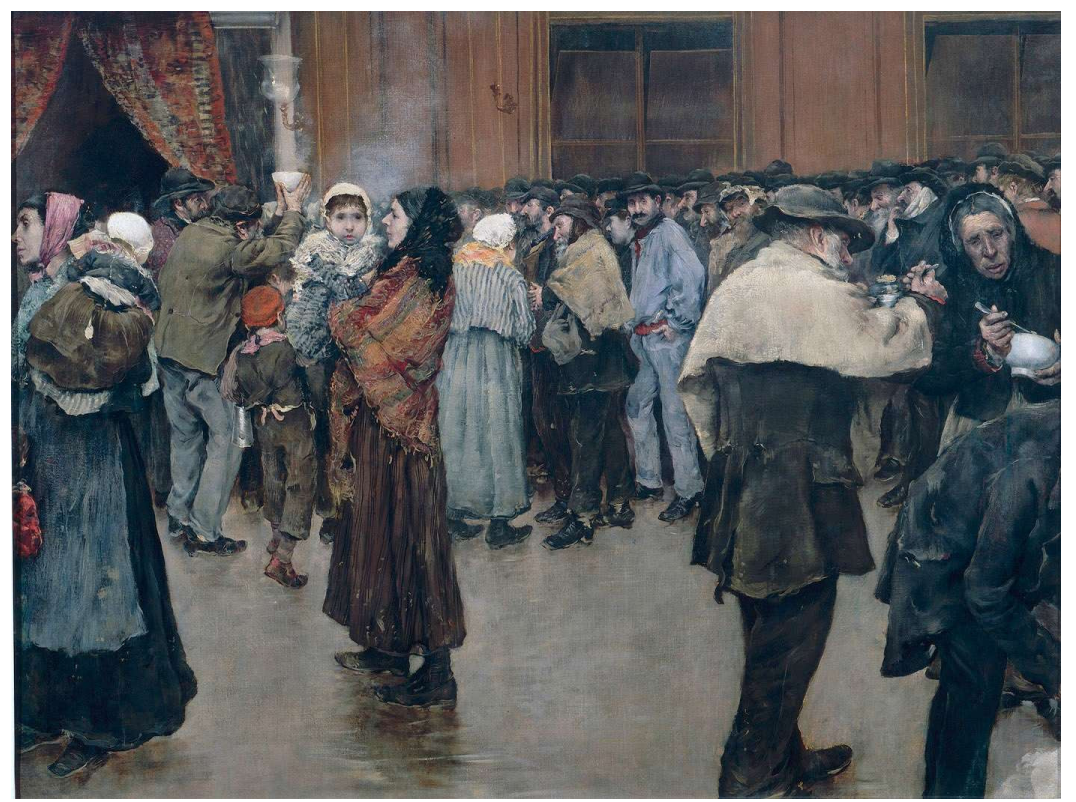

Norbert Goeneutte, La distribution de soupe aux pauvres à la porte du restaurant Brébant, 1880

Com uma riqueza de detalhes e com cores escuras, a La distribution de soupe aux pauvres à la porte du restaurant Brébant é uma obra que se distancia dos principais temas retratados pelos impressionistas. Observa-se que Norbet Goeneutte (1854-1894) retrata uma cena que passou a fazer parte da paisagem da cidade, em decorrência das constradições sociais impostas pelo modelo econômico capitalista: a distribuição de comida à população pauperizada de Paris.

De modo geral, em suas obras, os pintores impressionistas não assumiram uma concepção artística de caráter mais existencialista e, tampouco, desenvolveram um engajamento político, como, por exemplo, se constata no expressionismo (Cf. CASTRO, 2008).

\section{Considerações finais}

As peculiaridades existentes entre as ciências e as artes não as tornam campos diametralmente opostos e antagônicos entre si, como salientei no início deste escrito. Em suas criações, cientistas e artistas desenvolvem afinidades substanciais, principalmente por utilizarem uma imaginação criativa e por obstinadamente quererem compreender a "realidade", como relata Nisbet no trecho a seguir:

[...] Qualquer forma de arte que é séria, o romance, o poema ou a pintura, preocupa-se, primeiro e antes de tudo com a realidade. Ela está interessada em iluminar a realidade e comunicar de algum modo essa luz para os outros. 


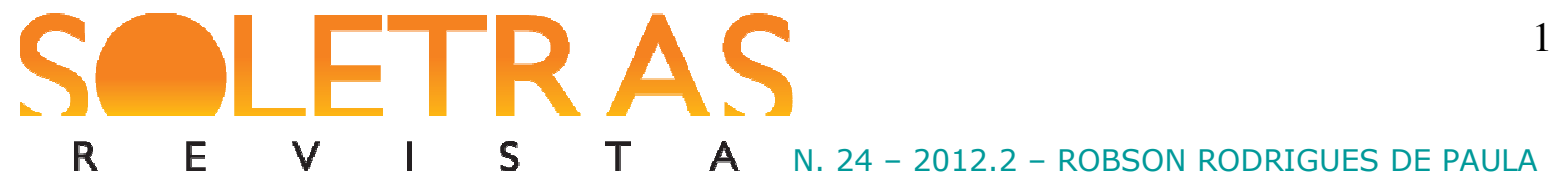

É com isso, basicamente, que a ciência - em contraste com a tecnologia - se preocupa. Eu ouso afirmar que há mais em comum entre Picasso e Eistein quanto a objetivo, inspiração e modo de realização - que entre Picasso e, digamos, Norman Rockwell ou entre Eistein e qualquer um dos frios praticantes do que A. N. Whitehead chamou uma vez "empirismo árido". Ambos, artistas e cientistas, são movidos pelo desejo de entender, de interpretar e de comunicar sua compreensão para o resto do mundo (NISBET, 2000, p. 116-117).

Ouso também em dizer que há muito em comum entre o interacionismo e a pintura impressionista, sobretudo a respeito dos procedimentos usados para expressar suas visões acerca das maneiras de ser e de agir dos indivíduos e de agrupamentos sociais na cidade moderna. Verifica-se que ambas as expressões humanas estiveram atentas às formas de relações sociais e as modalidades de apreensão dos lugares e espaços urbanos pelos atores sociais, ainda que com focos distintos e localizados em diferentes países. A pretensão de desvendar a "realidade" é compartilhada igualmente por estes profissionais. Enquanto que os sociólogos interacionistas pesquisaram, com tenacidade, as associações, disputas e conflitos estabelecidos entre indivíduos e grupos na Região Metropolitana de Chicago, tendo como proposta a indicação de possíveis iniciativas políticas para resolução das questões sociais; os impressionistas, meticulosamente, procuraram comunicar a forma com que percebiam os temas retratados, no exato momento de criação artística, pintando os jogos de luz e de sombras sobre os mesmos. Portanto, pode-se afirmar que crença de que é possível captar e entender o instante fugaz, o momento em que a ação se desenrola no aqui e agora, esteve presente nestes campos profissionais.

Por esta razão, tanto os interacionistas como artistas expoentes do modernismo na pintura desenvolveram modos de criação, os quais valorizavam a interação e o contato direto com o objeto a ser desvendado. Os primeiros fundamentaram suas análises a partir da observação participante - metodologia em que o pesquisador interage diretamente com o pesquisado, procurando compreender as percepções e os comportamentos dos "nativos" - e os segundos desenvolveram suas produções ao "ar livre", técnica artística que viabilizava um contato direto do artista com os indivíduos, objetos e lugares pintados.

Contudo, em si tratando dos objetivos da criação constata-se um distanciamento entre as referidas expressões humanas. Na primeira parte deste artigo, indiquei que, subjacente às pesquisas desenvolvidas pela Escola de Chicago havia um forte interesse moral - digamos que quase até religioso - de reforma social. Grosso modo, este grupo de pesquisadores atribuiu um caráter político à sociologia, uma vez que estabeleceram uma relação direta entre 


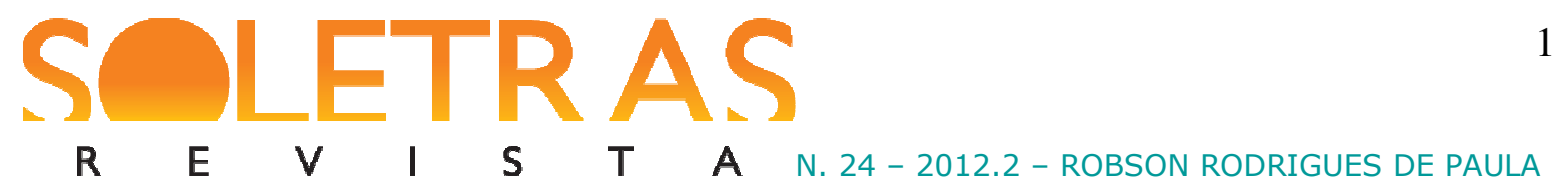

produção de conhecimento e intervenção política. Em contrapartida, como foi exposto posteriormente, os impressionistas não preferiram ressaltar, em seus quadros, às contradições sociais - embora se observe, em várias obras, situações que aludem uma preocupação com o impacto da reforma urbanística no tecido social parisiense. Foram capturados pelos "ventos modernos" e retrataram a cidade com um espetáculo, um palco dos locais de entretenimento e diversão das multidões amorfas. Entretanto, analisar este movimento pela falta ou atribuir-lhe um rótulo reducionista de "burguês" me parece equivocado. A não politização da pintura impressionista não ofusca a sua grande contribuição para o desenvolvimento das outras vertentes modernistas e para a história da arte como um todo.

O paradigma interacionista e a pintura impressionista são produções que dialogam entre si e com os seus respectivos cenários sociais e que, portanto, devem ser contextualizados historicamente e analisados de forma comparativa. Foi o que eu procurei fazer, de forma introdutória, neste escrito.

\section{Referências bibliográficas:}

BECKER, Howard S. A Escola de Chicago. Mana: Estudos de Antropologia Social, Rio de Janeiro, v. 2, n. 2, p. 177-188, ago.-dez. 1996.

BRADBURY, Malcolm; McFARLANE, James (Orgs.) Modernismo: guia geral (1890-1930). São Paulo: Companhia das Letras, 1999.

CASTRO, Márcio Sampaio. A modernidade como campo de tensão criativa para o impressionismo e o expressionismo: uma análise sóciopolítica. Anuário de Produção Acadêmica Docente, Campinas, SP, v. 2, n. 3, p. 391-400, ago.-dez. 2008.

CLARK. T. J. A pintura na vida moderna. São Paulo: Companhia das Letras, 2004.

FISHER, Berenice; STRAUSS, Anseln L. Interacionismo. BOTTOMORE, Tom; NISBET, Robert (Orgs.). História da análise sociológica. Rio de Janeiro: Zahar. 1980.

HARRISON, Charles. Modernismo: movimento da arte moderna. São Paulo: Cosac \& Naify, 2001.

HUYGHE, René. O poder da Imagem. Lisboa: Edições 70, 1998.

NISBET, Robert. A Sociologia como arte. Plural Sociologia, USP, São Paulo, v. 1, n. 7, p. 111, jan.-jun. 2000.

PARK, Robert. A cidade: sugestões para a investigação do comportamento humano no meio urbano. In: VELHO, Otávio (Org.). Fenômeno urbano. Rio de Janeiro: Zahar, 1973. 


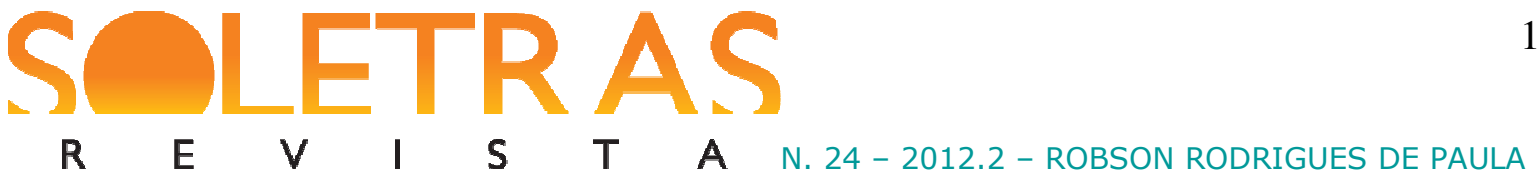

REYNOLD, Donald Martin. Introducción a la Historia del Arte: el siglo XIX. Barcelona, Editorial Gustavo Gili, 1990.

SCHAPIRO, Meier. Impressionismo. São Paulo: Cosac \& Naif, 2002.

SIMMEL, George. As grandes cidades e a vida do espírito. Mana: Estudos de Antropologia Social. Rio de Janeiro, v. 2, n. 11, p. 577-591, ago.-dez. 2005.

\title{
Filmografia de apoio:
}

http://www.maguetas.com.br/impressionismo/renoir/.

http://www.youtube.com/watch?v=j1-oQJWer2Y (acesso em 05- 12-2012).

http://www.youtube.com/watch?v=6FMcjxso_18\&list=HL1355397559\&feature=mh_lolz (acesso em 05-12-2012).

http://www.youtube.com/watch?v=ePsU6Gm6IbQ (acesso em 07-12-2012).

\section{Intersemiotic dialogues: interactionism and impressionist painting on stage}

\begin{abstract}
The formation of the greatest Western urban centres from the 19th century on has fostered significant changes in social relations and in the apprehension of public spaces by individuals. In the present essay, I analize the way Interactionism, an important sociological school, and the impressionistic painting comprehended or expressed, through their theoretical or aesthetical aspects, the matches and mismatches of individuals and social segments in Chicago, the locus of interactionist sociologists, and Paris, an important city to impressionistic painting. I defend, in this article, the existence of some points of contact beween both human expressions, especially regarding their procedures and techniques employed in the creative act.
\end{abstract}

Key words: Interactionism. Impressionist painting. Sociology of the art.

Recebido em: 22 de dezembro de 2012.

Aprovado em: 20 de janeiro de 2013. 